\title{
Urinary biomarkers of exposure to insecticides, herbicides, and one insect repellent among pregnant women in Puerto Rico
}

Ryan C Lewis ${ }^{1}$, David E Cantonwine ${ }^{2}$, Liza V Anzalota Del Toro ${ }^{3}$, Antonia M Calafat ${ }^{4}$, Liza Valentin-Blasini ${ }^{4}$, Mark D Davis ${ }^{4}$, Samuel E Baker ${ }^{4}$, Akram N Alshawabkeh ${ }^{5}$, José F Cordero ${ }^{3}$ and John D Meeker ${ }^{\text {** }^{*}}$

\begin{abstract}
Background: There are potential adverse health risks to the mother and fetus from exposure to pesticides. Thus, studies of exposure to pesticides among pregnant women are of interest as they will assist with understanding the potential burden of exposure globally, identifying sources of exposure, and designing epidemiology studies.

Methods: We measured urinary concentrations of the insect repellent N-N-diethyl-meta-toluamide (DEET) and two of its metabolites [3-diethyl-carbamoyl benzoic acid (DCBA) and $\mathrm{N}, \mathrm{N}$-diethyl-3-hydroxymethylbenzamide (DHMB)], four pyrethroid insecticide metabolites [4-fluoro-3-phenoxybenzoic acid (4-F-3-PBA); 3-phenoxybenzoic acid (3-PBA); trans-3-(2,2-dichlorovinyl)-2,2-dimethylcyclopropane carboxylic acid (trans-DCCA); and cis-3-(2,2-dibromovinyl)2,2-dimethylcyclopropane carboxylic acid (cis-DBCA)], and two chlorophenoxy herbicides [2,4-dichlorophenoxyacetic acid (2,4-D) and 2,4,5-trichlorophenoxyacetic acid (2,4,5-T)] in 54 pregnant women from Puerto Rico at three separate time points (20 \pm 2 weeks, $24 \pm 2$ weeks, and $28 \pm 2$ weeks of gestation). We calculated the distributions of the biomarker concentrations and compared them to those of women of reproductive age from the general U.S. population where available, and estimated the within-subject temporal variability of these repeated measurements. We also collected questionnaire data on demographics, consumption of select fruits, vegetables, and legumes in the past 48-hr, and pest-related issues, and associations between these variables and biomarker concentrations were examined.
\end{abstract}

Results: We found that 95th percentile urinary concentrations of DEET, 3-PBA, trans-DCCA, and 2,4-D were lower than women of reproductive age on the U.S. mainland, whereas 95th percentile urinary concentrations of 4-F-3-PBA, cis-DBCA, and 2,4,5-T were similar. DCBA, the only urinary biomarker detected in $>50 \%$ of the samples, showed fair to good reproducibility across pregnancy (intraclass correlation coefficient: 0.60 ). Women were more likely $(p<0.05)$ to have greater urinary concentrations of pesticide biomarkers if they were less educated (DCBA and trans-DCCA), unemployed (DHMB), or married (2,4-D), had consumed collards or spinach in past 48 -hr (2,4-D) or had been using insect repellent since becoming pregnant (DCBA), or were involved with residential applications of pesticides (trans-DCCA).

Conclusions: We identified concentrations and predictors of several pesticides among pregnant women in Puerto Rico. Further research is needed to understand what aspects of the predictors identified lead to greater exposure, and whether exposure during pregnancy is associated with adverse health.

Keywords: Biomarker, Pesticides, Pregnancy, Urine, Women

\footnotetext{
*Correspondence: meekerj@umich.edu

'Department of Environmental Health Sciences, University of Michigan

School of Public Health, 1415 Washington Heights, Ann Arbor, Ml 48109,

USA

Full list of author information is available at the end of the article
}

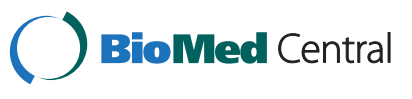

(c) 2014 Lewis et al.; licensee BioMed Central Ltd. This is an Open Access article distributed under the terms of the Creative Commons Attribution License (http://creativecommons.org/licenses/by/4.0), which permits unrestricted use, distribution, and reproduction in any medium, provided the original work is properly credited. The Creative Commons Public Domain Dedication waiver (http://creativecommons.org/publicdomain/zero/1.0/) applies to the data made available in this article, unless otherwise stated. 


\section{Background}

Pesticides refer to a broad class of chemicals that prevent, destroy, repel, or mitigate any pests [1], such as unwanted insects (insecticides, insect repellents), weeds (herbicides), microbes (fungicides, disinfectants), and mice and rats (rodenticides) [2]. Due to their widespread use, exposures to pesticides have been documented in humans globally. Pesticides such as the insect repellent $\mathrm{N}$-N-diethyl-meta-toluamide (DEET), the herbicides 2,4dichlorophenoxyacetic acid (2,4-D) and 2,4,5-trichlorophenoxyacetic acid $(2,4,5-\mathrm{T})$, and the metabolites of various pyrethroid insecticides (e.g., permethrin) have been measured in the urine of children [3-8] and adults $[9,10]$, including pregnant women [11-13]. These pesticides have also been measured in umbilical cord blood and sera [14,15] and meconium [16] of newborn humans, and the breast milk of lactating humans $[17,18]$ and other mammals $[19,20]$, which suggests that fetal and early postnatal exposure to these pesticides is possible.

In the general population, skin contact is the primary route of exposure to DEET (e.g., applied directly to skin or clothing or bedding that makes contact with skin) [21], whereas exposure to both pyrethroids and chlorophenoxy acids occurs mainly through ingestion of tainted crops $[20,22]$. However, depending on the scenario and population (e.g., occupational settings, improper product use), exposure to all of these pesticides may occur via several routes from a number of sources [20-22]. Epidemiology studies have linked exposures to pyrethroids or chlorophenoxy acids with lymphatic or blood cancers [6,23,24], and several adverse endocrine-related conditions, such as poor semen quality [25-28] and altered serum hormone levels [29]. In comparison, evidence of the impact of DEET on human health is limited and mostly derived from illness surveys and case reports [21]. Animal studies involving inhalation or oral exposures to DEET have demonstrated neurotoxicity of varying severity depending on the circumstances surrounding the exposures [21].

Despite the potential adverse health risks to both the mother and developing fetus, exposure studies in pregnant women have been limited for DEET, pyrethroids, and chlorophenoxy acids [11-13,30-32]. Thus, additional exposure studies are necessary, which will in turn assist with understanding the potential burden of exposure globally, identifying sources of exposure, and designing epidemiology studies. Pregnant women living in Puerto Rico are one at-risk and important population to study as Puerto Rico has an unexplained increase in adverse pregnancy outcomes such as preterm birth over the past several decades [33] and the island has a history of pesticide drift associated with agricultural operations [34], pesticide contaminated hazardous waste sites [35], use of illegal pesticides [36], and use of pesticides in illegal ways (e.g., applying non-approved pesticides to crops) [37].
The primary aims of this study were to: 1 ) describe distributions, 2) assess within-subject temporal variability, and 3) identify predictors of urinary concentrations of DEET and two of its metabolites, four metabolites of synthetic pyrethroids, and two chlorophenoxy acids in a cohort of pregnant women from Puerto Rico. To our knowledge, this is the first biomarker study to report on exposures to select pesticides among pregnant women in Puerto Rico.

\section{Methods}

\section{Study participants}

This analysis concerned 54 pregnant women participating in the Puerto Rico Test site for Exploring Contamination Threats (PROTECT) project. PROTECT is an ongoing prospective birth cohort in the northern karst region of Puerto Rico designed to assess the potential relationship between environmental toxicant exposures and risk of preterm birth and other adverse pregnancy outcomes [38,39]. Participants were recruited at approximately $14 \pm 2$ weeks of gestation at seven prenatal clinics and hospitals during 2010-2012. Pregnant women were eligible if they were 18-40 years of age, resided in a municipality within the northern karst region, received their first prenatal visit by the 20th week of pregnancy, did not use oral contraceptives three months prior to pregnancy or had in vitro fertilization as a method of assisted reproductive technology, and were free of known medical/obstetrics complications. Participants provided spot urine samples during three study visits at approximately $20 \pm 2$ weeks, $24 \pm 2$ weeks, and $28 \pm 2$ weeks of gestation. Questionnaires were also administered at each visit prior to collecting the urine to obtain information on demographics and self-reported consumption of fruits, vegetables, and legumes in the past 48-hr, and home pest-related issues. We also had questionnaire information on the use of insect repellent in the form sprays, lotions, or towelettes since becoming pregnant, which was collected from participants during visit 2 only. The study was described in detail to all participants who then gave informed consent. The Ethics and Research Committees of the University of Puerto Rico, the University of Michigan, and Northeastern University approved the research protocol. The involvement of the Centers for Disease Control and Prevention (CDC) did not constitute engagement in human subject research.

\section{Urinary biomarkers of pesticide exposure}

At each study visit, participants provided one spot urine sample, which was collected and processed using procedures that were comparable to those the CDC has developed for the National Health and Nutrition Examination Survey (NHANES) and other studies. Urine samples were analyzed at the National Center for Environmental Health of the CDC (Atlanta, GA, USA) for the following 
9 biomarkers: DEET and two of its metabolites, 3-diethylcarbamoyl benzoic acid (DCBA) and N,N-diethyl-3hydroxymethylbenzamide (DHMB); four metabolites of synthetic pyrethroids, 4-fluoro-3-phenoxybenzoic acid (4-F-3-PBA), 3-phenoxybenzoic acid (3-PBA), trans-3(2,2-dichlorovinyl)-2,2-dimethylcyclopropane carboxylic acid (trans-DCCA), and cis-3-(2,2-dibromovinyl)-2,2-dimethylcyclopropane carboxylic acid (cis-DBCA); and two chlorophenoxy herbicides, 2,4-D and 2,4,5-T. The urinalysis used solid phase extraction and high-performance liquid chromatography-isotope dilution tandem mass spectrometry as described previously $[40,41]$. Accuracy and precision for each analytical run were monitored through the use of calibration standards, reagent blanks, and quality control materials of high and low concentrations. For analyses concerning imputation of left-censored urinary concentrations (Table 1, Figure 1, and DCBA analyses in Tables 2, 3 and 4), concentrations below the limit of detection (LOD) were assigned a value of LOD divided by the square root of 2 . Where adjustment for urinary output was necessary (Figure 1 and DCBA analyses in Tables 2, 3 and 4), urinary concentrations were corrected for specific gravity (SG), which was measured at the University of Puerto Rico using a digital handheld refractometer (Atago Co., Ltd., Tokyo, Japan), using the following formula: $P_{c}=P_{m}\left[\left(S G_{p}-1\right) /\left(S G_{m}-1\right)\right]$, where
$P_{c}$ is the SG-corrected urinary concentration $(\mathrm{ng} / \mathrm{ml})$, $P_{m}$ is the measured urinary concentration $(\mathrm{ng} / \mathrm{ml}), S G_{p}$ is the median of the urinary SGs for the population (1.019), and $S G_{m}$ is the measured urinary SG.

\section{Statistical analysis}

Statistical analysis was performed using SAS version 9.3 for Windows (SAS Institute, Cary, NC, USA). Distributions of urinary concentrations were calculated and compared to those measured in U.S. women 18-40 years of age from NHANES where available (www.cdc.gov/ nchs/nhanes.htm). In further statistical analyses, we excluded biomarkers that were detected in less than $5 \%$ of the samples (DEET, 4-F-3-PBA, cis-DBCA, and 2,4,5-T). To assess between- and within-subject variability in urinary concentrations over the three study visits, intraclass correlation coefficients (ICCs) were calculated using variance components derived from linear mixed models with a random subject effect only for log-transformed analyte concentrations detected in at least $50 \%$ of the samples (DCBA only). The corresponding 95\% confidence intervals (CIs) associated with the ICCs were also calculated [42]. The magnitude of the ICCs was interpreted using the following criteria: poor reproducibility (ICC <0.40), fair to good reproducibility $(0.40 \leq \mathrm{ICC}<0.75)$, and excellent reproducibility (ICC $\geq 0.75$ ) [43]. To assess whether

Table 1 Urinary concentrations of pesticide biomarkers ( $\mathrm{ng} / \mathrm{ml}$, uncorrected for SG) in pregnant women from PROTECT (Puerto Rico) and comparison with women ages 18-40 from NHANES (U.S. population-based sample)

\begin{tabular}{|c|c|c|c|c|c|c|c|c|c|c|c|c|}
\hline \multirow[b]{2}{*}{ Chemical class } & \multirow[b]{2}{*}{ Parent compound(s) } & \multirow[b]{2}{*}{ Analyte } & \multirow[b]{2}{*}{ LOD } & \multirow[b]{2}{*}{ Study and year } & \multirow[b]{2}{*}{$\mathrm{N}$} & \multirow[b]{2}{*}{$N(\%) \geq$ LOD } & \multirow[b]{2}{*}{ GM } & \multicolumn{5}{|c|}{ Percentiles } \\
\hline & & & & & & & & 25th & 50th & 75th & 95th & Max \\
\hline \multirow[t]{4}{*}{ Insect repellent } & DEET & DEET & 0.1 & PROTECT 10-12 & $152^{\mathrm{a}}$ & $5(3.3)$ & $<L O D$ & $<L O D$ & $<L O D$ & $<\mathrm{LOD}$ & $<L O D$ & 3.3 \\
\hline & & & 0.1 & NHANES 01-02 & 456 & $67(14.7)$ & $<\mathrm{LOD}$ & $<L O D$ & $<L O D$ & $<\mathrm{LOD}$ & 0.2 & 57.3 \\
\hline & & DCBA & 1.0 & PROTECT 10-12 & $152^{\mathrm{a}}$ & $120(79.0)$ & 4.1 & 1.3 & 3.5 & 9.0 & 59.0 & 1856 \\
\hline & & DHMB & 0.1 & PROTECT 10-12 & $152^{\mathrm{a}}$ & $36(23.7)$ & $<\mathrm{LOD}$ & $<L O D$ & $<L O D$ & $<\mathrm{LOD}$ & 0.5 & 32.8 \\
\hline \multirow[t]{8}{*}{ Pyrethroid insecticide } & Cyfluthrin & 4-F-3-PBA & 0.1 & PROTECT 10-12 & $116^{\mathrm{b}}$ & $0(0.0)$ & $<\mathrm{LOD}$ & $<L O D$ & $<\mathrm{LOD}$ & $<\mathrm{LOD}$ & $<L O D$ & $<\mathrm{LOD}$ \\
\hline & & & 0.1 & NHANES 07-08 & 364 & $21(5.8)$ & $<L O D$ & $<L O D$ & $<L O D$ & $<L O D$ & $<L O D$ & 4.6 \\
\hline & $\begin{array}{l}\text { Cyhalothrin, Cypermethrin, } \\
\text { Deltamethrin, Fenpropathrin, } \\
\text { Permethrin, Tralomethrin }\end{array}$ & 3-PBA & 0.1 & PROTECT 10-12 & $141^{c}$ & $65(46.1)$ & 0.2 & $<L O D$ & $<\mathrm{LOD}$ & 0.6 & 2.3 & 11.3 \\
\hline & & & 0.1 & NHANES 07-08 & 339 & $235(69.3)$ & 0.4 & $<L O D$ & 0.4 & 1.1 & 6.5 & 36.8 \\
\hline & $\begin{array}{l}\text { Cypermethrin, Cyfluthrin, } \\
\text { Permethrin }\end{array}$ & trans-DCCA & 0.6 & PROTECT 10-12 & $152^{\mathrm{a}}$ & $11(7.2)$ & $<\mathrm{LOD}$ & $<L O D$ & $<\mathrm{LOD}$ & $<\mathrm{LOD}$ & 2.4 & 7.6 \\
\hline & & & 0.6 & NHANES 07-08 & 362 & $54(14.9)$ & $<\mathrm{LOD}$ & $<L O D$ & $<L O D$ & $<L O D$ & 3.3 & 29.0 \\
\hline & Deltamethrin & cis-DBCA & 0.5 & PROTECT 10-12 & $152^{\mathrm{a}}$ & $0(0.0)$ & $<\mathrm{LOD}$ & $<L O D$ & $<\mathrm{LOD}$ & $<L O D$ & $<L O D$ & $<\mathrm{LOD}$ \\
\hline & & & 0.5 & NHANES 07-08 & 364 & $5(1.4)$ & $<\mathrm{LOD}$ & $<L O D$ & $<L O D$ & $<L O D$ & $<L O D$ & 1.8 \\
\hline \multirow{4}{*}{$\begin{array}{l}\text { Chlorophenoxy } \\
\text { herbicide }\end{array}$} & $2,4-D$ & $2,4-\mathrm{D}$ & 0.4 & PROTECT 10-12 & $152^{\mathrm{a}}$ & $18(11.8)$ & $<\mathrm{LOD}$ & $<L O D$ & $<\mathrm{LOD}$ & $<\mathrm{LOD}$ & 0.6 & 0.9 \\
\hline & & & 0.4 & NHANES 07-08 & 364 & $121(33.2)$ & $<\mathrm{LOD}$ & $<L O D$ & $<L O D$ & 0.5 & 1.1 & 8.3 \\
\hline & $2,4,5-\mathrm{T}$ & $2,4,5-\mathrm{T}$ & 0.1 & PROTECT 10-12 & $152^{\mathrm{a}}$ & $0(0.0)$ & $<\mathrm{LOD}$ & $<L O D$ & $<L O D$ & $<L O D$ & $<L O D$ & $<\mathrm{LOD}$ \\
\hline & & & 0.1 & NHANES 07-08 & 364 & $3(0.8)$ & $<\mathrm{LOD}$ & $<L O D$ & $<\mathrm{LOD}$ & $<\mathrm{LOD}$ & $<L O D$ & 1.2 \\
\hline
\end{tabular}




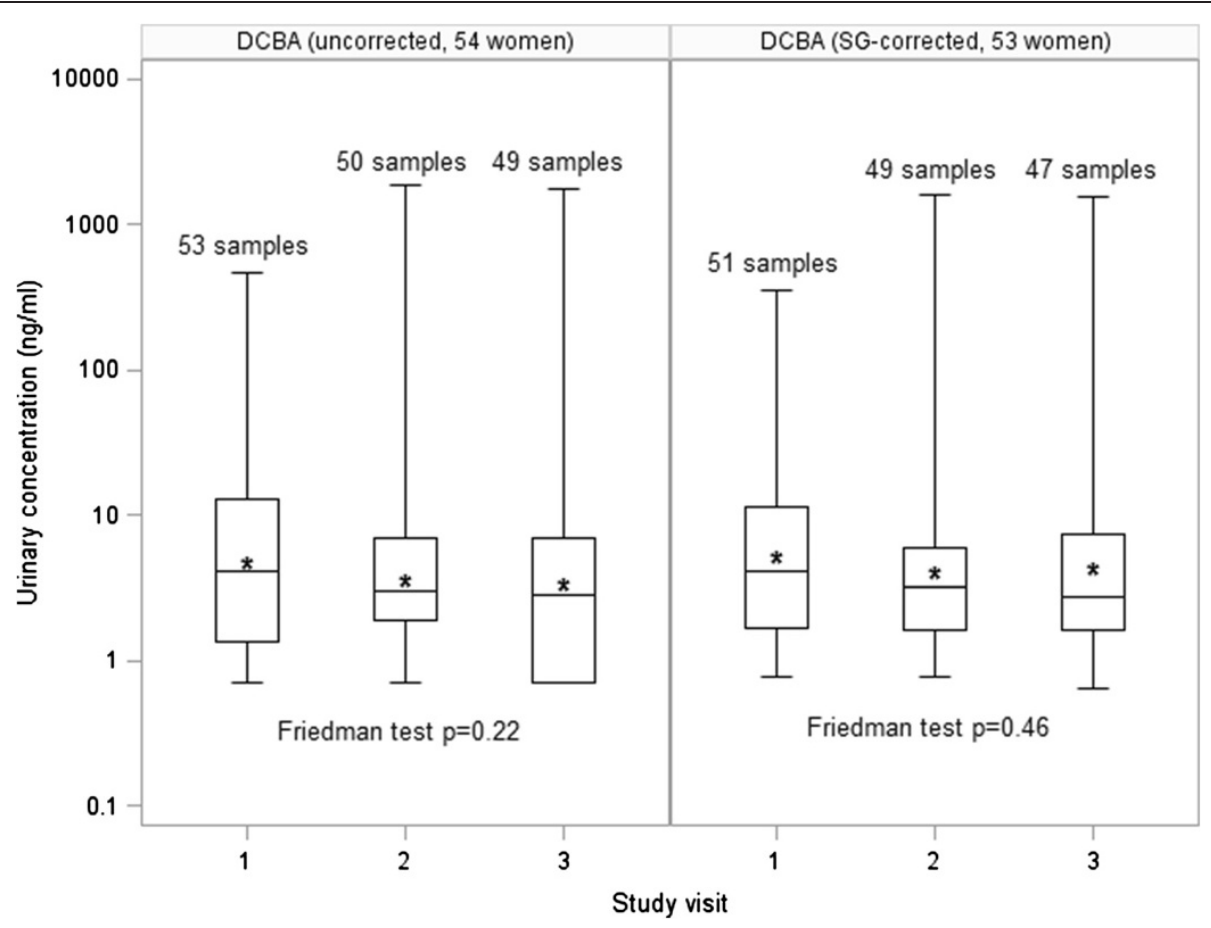

Figure 1 Distributions of urinary concentrations of DCBA $(\mathrm{ng} / \mathrm{ml})$ in pregnant women between study visits $(20 \pm 2$ weeks of gestation $=$ visit $1,24 \pm 2$ weeks of gestation $=$ visit 2 , and $28 \pm 2$ weeks of gestation $=$ visit 3 ). Boxes represent the interquartile range; horizontal lines represent the minimum, median, and maximum; and asterisks represent the geometric mean. Sample sizes differ between uncorrected and SG-corrected analyses because SG was not available for some samples.

Table 2 Associations between time of urine collection or demographic characteristics and urinary concentrations of pesticide biomarkers

\begin{tabular}{|c|c|c|c|c|c|c|c|c|c|c|}
\hline \multirow[t]{2}{*}{ Variable } & \multicolumn{2}{|c|}{$\mathrm{DCBA}^{\mathrm{a}}$} & \multicolumn{2}{|l|}{ DHMB } & \multicolumn{2}{|l|}{ 3-PBA } & \multicolumn{2}{|c|}{ trans-DCCA } & \multicolumn{2}{|l|}{ 2,4-D } \\
\hline & $\mathbf{N}$ & $\beta(95 \% \mathrm{Cl})^{\mathrm{b}}$ & $\mathrm{N}(\geq \mathrm{LOD})$ & OR $(95 \% \mathrm{Cl})^{\mathrm{c}}$ & $\mathrm{N}(\geq \mathrm{LOD})$ & OR $(95 \% \mathrm{Cl})^{\mathrm{c}}$ & $\mathrm{N}(\geq \mathrm{LOD})$ & OR $(95 \% \mathrm{Cl})^{\mathrm{c}}$ & $\mathrm{N}(\geq \mathrm{LOD})$ & OR $(95 \% \mathrm{CI})^{\mathrm{c}}$ \\
\hline \multicolumn{11}{|c|}{ Time of day } \\
\hline PM & 65 & $0.0(-0.4,0.4)$ & $67(18)$ & $1.4(0.7,2.8)$ & $61(29)$ & $1.1(0.5,2.2)$ & $67(5)$ & $1.1(0.3,4.0)$ & $67(11)$ & $2.2(0.8,6.1)$ \\
\hline AM & 82 & & 85 (18) & 1.0 & $80(36)$ & 1.0 & $85(6)$ & 1.0 & $85(7)$ & 1.0 \\
\hline \multicolumn{11}{|c|}{ Age (years) } \\
\hline$<24$ & 76 & $0.3(-0.4,1.0)$ & 80 (18) & $0.9(0.4,2.0)$ & $75(36)$ & $1.2(0.6,2.4)$ & $80(8)$ & $2.6(0.7,9.8)$ & $80(11)$ & $1.5(0.4,5.2)$ \\
\hline$\geq 24$ & 71 & & 72 (18) & 1.0 & $66(29)$ & 1.0 & $72(3)$ & 1.0 & $72(7)$ & 1.0 \\
\hline \multicolumn{11}{|c|}{ Educ. (years) } \\
\hline$\leq 12$ & 33 & $0.9(0.1,1.7)^{*}$ & $36(11)$ & $1.6(0.6,4.2)$ & $32(16)$ & $1.2(0.5,3.0)$ & $36(6)$ & $4.4(1.3,15.6)^{*}$ & $36(2)$ & $0.4(0.1,1.6)$ \\
\hline$>12$ & 114 & & $116(25)$ & 1.0 & 109 (49) & 1.0 & $116(5)$ & 1.0 & $116(16)$ & 1.0 \\
\hline \multicolumn{11}{|l|}{ Married } \\
\hline Yes & 67 & $0.0(-0.4,0.4)$ & $68(12)$ & $0.5(0.2,1.2)$ & $65(33)$ & $1.5(0.7,3.1)$ & $68(4)$ & $0.8(0.2,2.9)$ & $68(13)$ & $3.5(1.5,8.4)^{*}$ \\
\hline No & 79 & & $80(23)$ & 1.0 & $73(30)$ & 1.0 & $80(6)$ & 1.0 & $80(5)$ & 1.0 \\
\hline \multicolumn{11}{|c|}{ Unemployed } \\
\hline Yes & 43 & $-0.5(-1.2,0.2)$ & 43 (16) & $2.7(1.1,6.3)^{*}$ & $36(15)$ & $0.8(0.4,1.8)$ & $43(3)$ & $1.1(0.3,4.3)$ & $43(5)$ & $0.9(0.3,3.1)$ \\
\hline No & 103 & & 105 (19) & 1.0 & $102(48)$ & 1.0 & $105(7)$ & 1.0 & 105 (13) & 1.0 \\
\hline
\end{tabular}

Abbreviations: $\beta$ beta coefficient, $C l$ confidence interval, $L O D$ limit of detection, $O R$ odds ratio.

${ }^{a}$ Biomarker concentration was sg-corrected and log-transformed; ${ }^{b} \beta$ and associated $95 \% \mathrm{Cl}$ calculated using a linear mixed model with a random subject effect and a fixed effect for time of urine collection or demographic characteristic; ${ }^{\mathrm{C}} \mathrm{OR}$ and $95 \% \mathrm{Cl}$ calculated using a generalized estimating equation with a fixed effect for time of urine collection or demographic characteristic; ${ }^{*} p<0.05$. 
Table 3 Associations between select food items consumed in the past 48-hr and urinary concentrations of pesticide biomarkers

\begin{tabular}{|c|c|c|c|c|c|c|c|c|c|c|}
\hline \multirow[t]{2}{*}{ Variable } & \multicolumn{2}{|c|}{$D_{C B A^{a}}$} & \multicolumn{2}{|l|}{ DHMB } & \multicolumn{2}{|l|}{ 3-PBA } & \multicolumn{2}{|c|}{ trans-DCCA } & \multicolumn{2}{|l|}{$2,4-D$} \\
\hline & $\bar{N}$ & $\beta(95 \% \mathrm{Cl})^{\mathrm{b}}$ & $\bar{N}(\geq$ LOD $)$ & OR $(95 \% \mathrm{CI})^{\mathrm{c}}$ & $\mathrm{N}(\geq \mathrm{LOD})$ & $\overline{\text { OR }(95 \% \mathrm{CI})^{\mathrm{c}}}$ & $\bar{N}(\geq$ LOD $)$ & $\overline{\text { OR }(95 \% \mathrm{CI})^{\mathrm{c}}}$ & $\mathrm{N}(\geq \mathrm{LOD})$ & OR $(95 \% \mathrm{CI})^{c}$ \\
\hline \multicolumn{11}{|l|}{ Apples } \\
\hline Yes & 27 & $0.1(-0.5,0.6)$ & $28(8)$ & $1.4(0.6,3.3)$ & $26(11)$ & $0.9(0.4,2.0)$ & $28(2)$ & $1.2(0.3,5.5)$ & $28(3)$ & $0.9(0.3,2.7)$ \\
\hline No & 113 & & $114(25)$ & 1.0 & $106(49)$ & 1.0 & $114(7)$ & 1.0 & $114(13)$ & 1.0 \\
\hline \multicolumn{11}{|l|}{ Cherries } \\
\hline Yes & 8 & $0.3(-0.6,1.2)$ & $9(2)$ & $0.9(0.2,4.3)$ & $8(1)$ & $0.2(0.0,1.5)$ & $9(1)$ & $2.0(0.2,19.2)$ & $9(1)$ & $1.0(0.1,7.0)$ \\
\hline No & 132 & & $133(31)$ & 1.0 & $124(59)$ & 1.0 & $133(8)$ & 1.0 & $133(15)$ & 1.0 \\
\hline \multicolumn{11}{|l|}{ Collards } \\
\hline Yes & 5 & $-0.2(-1.4,0.9)$ & $5(1)$ & $0.8(0.1,7.9)$ & $5(3)$ & $1.8(0.2,14.5)$ & $5(0)$ & - & $5(2)$ & $5.9(1.3,26.7)^{*}$ \\
\hline No & 135 & & $137(32)$ & 1.0 & $127(57)$ & 1.0 & $137(9)$ & 1.0 & $137(14)$ & 1.0 \\
\hline \multicolumn{11}{|l|}{ Grapes } \\
\hline Yes & 48 & $-0.1(-0.5,0.4)$ & $49(9)$ & $0.6(0.3,1.6)$ & $45(16)$ & $0.5(0.2,1.2)$ & $49(2)$ & $0.5(0.1,2.5)$ & $49(6)$ & $1.2(0.3,3.8)$ \\
\hline No & 92 & & $93(24)$ & 1.0 & $87(44)$ & 1.0 & $93(7)$ & 1.0 & $93(10)$ & 1.0 \\
\hline \multicolumn{11}{|c|}{ Grape juice } \\
\hline Yes & 55 & $-0.4(-0.8,0.1)$ & $55(9)$ & $0.5(0.2,1.2)$ & $49(20)$ & $0.7(0.4,1.4)$ & $55(4)$ & $1.3(0.3,5.5)$ & $55(6)$ & $0.9(0.4,2.3)$ \\
\hline No & 85 & & $87(24)$ & 1.0 & $83(40)$ & 1.0 & $87(5)$ & 1.0 & $87(10)$ & 1.0 \\
\hline \multicolumn{11}{|l|}{ Peanuts } \\
\hline Yes & 21 & $-0.4(-0.9,0.1)$ & $22(3)$ & $0.5(0.1,2.3)$ & $20(7)$ & $0.6(0.2,1.6)$ & $22(2)$ & $1.6(0.3,9.4)$ & $22(2)$ & $0.8(0.2,2.9)$ \\
\hline No & 119 & & $120(30)$ & 1.0 & $112(53)$ & 1.0 & $120(7)$ & 1.0 & $120(14)$ & 1.0 \\
\hline \multicolumn{11}{|c|}{ Peanut butter } \\
\hline Yes & 14 & $-0.4(-1.1,0.3)$ & $14(4)$ & $1.4(0.5,3.9)$ & $13(6)$ & $1.0(0.3,3.3)$ & $14(2)$ & $2.9(0.6,15.1)$ & $14(1)$ & $0.6(0.1,5.1)$ \\
\hline No & 126 & & $128(29)$ & 1.0 & $119(54)$ & 1.0 & $128(7)$ & 1.0 & $128(15)$ & 1.0 \\
\hline \multicolumn{11}{|l|}{ Raisins } \\
\hline Yes & 15 & $-0.4(-1.1,0.3)$ & $16(2)$ & $0.4(0.1,2.0)$ & $15(6)$ & $0.8(0.4,1.6)$ & $16(1)$ & $1.0(0.1,8.8)$ & $16(1)$ & $0.5(0.1,4.4)$ \\
\hline No & 125 & & $126(31)$ & 1.0 & $117(54)$ & 1.0 & $126(8)$ & 1.0 & $126(15)$ & 1.0 \\
\hline \multicolumn{11}{|l|}{ Spinach } \\
\hline Yes & 6 & $-0.6(-1.6,0.3)$ & $6(0)$ & - & $6(3)$ & $1.2(0.2,8.1)$ & $6(1)$ & $3.2(0.3,33.2)$ & $6(2)$ & $4.4(1.1,17.9)^{*}$ \\
\hline No & 134 & & $136(33)$ & 1.0 & $126(57)$ & 1.0 & $136(8)$ & 1.0 & $136(14)$ & 1.0 \\
\hline \multicolumn{11}{|c|}{ Strawberries } \\
\hline Yes & 33 & $-0.1(-0.6,0.4)$ & $34(8)$ & $1.0(0.4,2.5)$ & $34(12)$ & $0.6(0.3,1.3)$ & $34(3)$ & $1.6(0.5,5.7)$ & $34(3)$ & $0.7(0.2,2.8)$ \\
\hline No & 107 & & $108(25)$ & 1.0 & $98(48)$ & 1.0 & $108(6)$ & 1.0 & $108(13)$ & 1.0 \\
\hline \multicolumn{11}{|c|}{ Tomatoes } \\
\hline Yes & 59 & $0.1(-0.3,0.5)$ & $60(13)$ & $0.9(0.4,1.8)$ & $56(25)$ & $0.9(0.5,1.9)$ & $60(6)$ & $2.9(0.7,13.2)$ & $60(5)$ & $0.6(0.2,1.8)$ \\
\hline No & 81 & & $82(20)$ & 1.0 & $76(35)$ & 1.0 & $82(3)$ & 1.0 & $82(11)$ & 1.0 \\
\hline
\end{tabular}

Abbreviations: $\beta$ beta coefficient, $\mathrm{Cl}$ confidence interval, $L O D$ limit of detection, OR odds ratio.

aiomarker concentration was sg-corrected and log-transformed; ${ }^{b} \beta$ and associated $95 \% \mathrm{Cl}$ calculated using a linear mixed model with a random subject effect and a fixed effect for food consumed in the past $48-\mathrm{hr} ;{ }^{\mathrm{C}} \mathrm{OR}$ and $95 \% \mathrm{Cl}$ calculated using a generalized estimating equation with a fixed effect for food consumed in the past $48-\mathrm{hr} ;{ }^{*} p<0.05$.

or not there are trends in urinary concentrations over pregnancy, we also ran a Friedman test, a non-parametric equivalent of the repeated measures analysis of variance test, for analytes detected in at least $50 \%$ of the samples. To identify predictors of pesticide exposure, we also examined the associations between time of urine collection, demographic characteristics, select food items consumed in the past 48-hr, or pest-related issues and urinary concentrations of the analytes in one of two ways. For biomarkers detected in less than $50 \%$ of the samples (DHMB, 3-PBA, trans-DCCA, and 2,4-D), we estimated the odds of having a detectable biomarker concentration 
Table 4 Associations between pest-related issues and urinary concentrations of pesticide biomarkers

\begin{tabular}{|c|c|c|c|c|c|c|c|c|c|c|}
\hline \multirow[t]{2}{*}{ Variable } & \multicolumn{2}{|c|}{$\mathrm{DCBA}^{\mathrm{a}}$} & \multicolumn{2}{|l|}{ DHMB } & \multicolumn{2}{|l|}{ 3-PBA } & \multicolumn{2}{|c|}{ trans-DCCA } & \multicolumn{2}{|l|}{ 2,4-D } \\
\hline & $\bar{N}$ & $\beta(95 \% \mathrm{Cl})^{\mathrm{b}}$ & $\mathrm{N}(\geq \mathrm{LOD})$ & $\overline{\text { OR }(95 \% \mathrm{Cl})^{c}}$ & $\mathrm{~N}(\geq \mathrm{LOD})$ & $\overline{\text { OR }(95 \% \mathrm{Cl})^{c}}$ & $\mathrm{~N}(\geq \mathrm{LOD})$ & OR $(95 \% \mathrm{Cl})^{c}$ & $\mathrm{~N}(\geq \mathrm{LOD})$ & OR $(95 \% \mathrm{Cl})^{\mathrm{c}}$ \\
\hline \multicolumn{11}{|c|}{ Insects (inside) $^{d}$} \\
\hline Yes & 71 & $0.2(-0.2,0.7)$ & $73(20)$ & $1.6(0.7,3.9)$ & $69(35)$ & $1.6(0.8,3.2)$ & $73(9)$ & - & $73(7)$ & $0.7(0.2,2.2)$ \\
\hline No & 69 & & $69(13)$ & 1.0 & $63(25)$ & 1.0 & $69(0)$ & 1.0 & $69(9)$ & 1.0 \\
\hline \multicolumn{11}{|c|}{ Pesticides (inside) ${ }^{\mathrm{e}}$} \\
\hline Yes & 6 & $-0.2(-1.2,0.8)$ & $7(1)$ & $0.5(0.1,5.0)$ & $6(1)$ & $0.2(0.0,2.1)$ & $7(1)$ & $2.6(0.3,26.2)$ & $7(0)$ & - \\
\hline No & 134 & & $135(32)$ & 1.0 & $126(59)$ & 1.0 & $135(8)$ & 1.0 & $135(16)$ & 1.0 \\
\hline \multicolumn{11}{|c|}{ Pesticides (inside) ${ }^{f}$} \\
\hline Yes & 31 & $0.3(-0.2,0.7)$ & $32(9)$ & $1.4(0.5,3.6)$ & $29(15)$ & $1.4(0.6,3.4)$ & $32(5)$ & $4.9(1.1,22.1)^{*}$ & $32(2)$ & $0.5(0.1,2.2)$ \\
\hline No & 109 & & $110(24)$ & 1.0 & $103(45)$ & 1.0 & $110(4)$ & 1.0 & $110(14)$ & 1.0 \\
\hline \multicolumn{11}{|c|}{ Pesticides (outside) ${ }^{g}$} \\
\hline Yes & 11 & $0.3(-0.4,1.0)$ & $11(2)$ & $0.7(0.1,3.6)$ & $11(5)$ & $1.0(0.3,3.3)$ & $11(1)$ & $1.5(0.2,13.8)$ & $11(1)$ & $0.8(0.1,6.7)$ \\
\hline No & 128 & & $130(31)$ & 1.0 & $120(55)$ & 1.0 & $130(8)$ & 1.0 & $130(15)$ & 1.0 \\
\hline \multicolumn{11}{|c|}{ Pesticides (home/lawn) ${ }^{\text {h }}$} \\
\hline Yes & 16 & $0.6(-0.0,1.2)$ & $17(7)$ & $2.7(0.9,8.0)$ & $17(10)$ & $1.9(0.6,5.9)$ & $17(3)$ & $4.3(0.7,24.7)$ & $17(1)$ & $0.5(0.1,4.0)$ \\
\hline No & 124 & & $125(26)$ & 1.0 & $115(50)$ & 1.0 & $125(6)$ & 1.0 & $125(15)$ & 1.0 \\
\hline \multicolumn{11}{|c|}{ Pesticides(stored) ${ }^{i}$} \\
\hline Yes & 95 & $-0.4(-0.9,0.0)$ & $97(20)$ & $0.6(0.3,1.4)$ & $92(41)$ & $0.9(0.4,2.0)$ & $97(7)$ & $1.7(0.3,9.1)$ & $97(8)$ & $0.4(0.1,1.5)$ \\
\hline No & 45 & & $45(13)$ & 1.0 & $40(19)$ & 1.0 & $45(2)$ & 1.0 & $45(8)$ & 1.0 \\
\hline \multicolumn{11}{|c|}{ Insect repellent ${ }^{j}$} \\
\hline Yes & 16 & $1.2(0.4,2.0)^{*}$ & $17(6)$ & $0.3(0.1,1.3)$ & $17(8)$ & $0.7(0.2,2.3)$ & $17(3)$ & $0.1(0.0,1.5)$ & $17(3)$ & $0.8(0.1,5.0)$ \\
\hline No & 33 & & $33(5)$ & 1.0 & $29(11)$ & 1.0 & $33(1)$ & 1.0 & $33(2)$ & 1.0 \\
\hline
\end{tabular}

Abbreviations: $\beta$ beta coefficient, $C l$ confidence interval, LOD limit of detection OR odds ratio.

${ }^{a}$ Biomarker concentration was sg-corrected and log-transformed; ${ }^{b} \beta$ and associated $95 \% \mathrm{Cl}$ calculated using a linear mixed model with a random subject effect and a fixed effect for pest-related issue; ${ }^{c} \mathrm{OR}$ and $95 \% \mathrm{Cl}$ calculated using a generalized estimating equation with a fixed effect for home pest-related issue; ${ }^{{ }^{i}}$ insects a common nuisance inside home; ${ }^{\mathrm{e}}$ pesticides applied inside home by a professional exterminator regardless of time since last application; ${ }^{f}$ pesticides applied inside home by participant regardless of time since last application; ${ }^{9}$ pesticides applied outside home by participant regardless of time since last application; ${ }^{h}$ pesticides applied to home or lawn by participant in past 48-hr; ${ }^{i}$ pesticides currently stored inside home; ${ }^{j}$ insect repellent spray, lotion, or towelette use since becoming pregnant (information was collected at visit 2 only, thus effect estimates were derived from linear or logistic regression models); ${ }^{*} p<0.05$.

given a particular variable (e.g., consumed apples in the past 48-hr) relative to the odds of the outcome in the absence of that variable (e.g., did not consume apples in the past 48-hr). In other words, these statistical models relied on binary exposure data that assigned a participant a "yes" if the biomarker was detected or a "no" if the biomarker was not detected. We reported the associations as odds ratios (ORs) along with their associated 95\% CIs, which were calculated using generalized estimating equations to account for repeated measures with a fixed effect for the predictor of interest. In this case, we gave consideration to modeling urinary biomarker concentrations as a continuous variable, but we chose a binary outcome approach (i.e., detect or non-detect) as the former would require the imputation of too many left censored values for many of the biomarkers (e.g., 92.8\% of values for trans-DCCA) and, as a result, may not be the most valid statistical approach. On the other hand, for analytes detected in at least $50 \%$ of the samples, we modeled urinary biomarker concentrations as a log-transformed continuous variable and reported the beta coefficients along with their associated 95\% CIs, which were calculated using linear mixed effect models to account for repeated measures with a random subject effect and a fixed effect for the predictor of interest. Because information on insect repellent use was only collected during visit 2 , statistical models accounting for repeated measurements were not necessary and, as a result, associations with visit 2 biomarker concentrations were assessed using either logistic or linear regression models for that variable. We only assessed those questionnaire items with $\mathrm{N} \geq 5$ in the "Yes" and "No" groups. Finally, for exposure biomarkers with multiple significant predictors, to explore confounding we constructed multivariable models where these predictors were included simultaneously.

\section{Results}

Table 1 shows the distributions of the urinary biomarkers relative to those in U.S. women ages 18-40 from NHANES. In this sample of pregnant Puerto Rican 
women, 152 urine samples were available for analysis for most analytes, except for 4-F-3-PBA $(\mathrm{N}=116)$ and 3-PBA $(\mathrm{N}=141)$ due to quality control issues and the presence of interfering compound(s) in the urine, respectively. All analytes were detected in fewer than $50 \%$ of the samples, except DCBA, which was detected in $79 \%$. Ninety-fifth percentile urinary concentrations of DEET $(<\mathrm{LOD}=0.1 \mathrm{ng} / \mathrm{ml}$ vs. $0.2 \mathrm{ng} / \mathrm{ml}), 3-\mathrm{PBA}(2.3 \mathrm{ng} / \mathrm{ml}$ vs. $6.5 \mathrm{ng} / \mathrm{ml})$, trans-DCCA $(2.4 \mathrm{ng} / \mathrm{ml}$ vs. $3.3 \mathrm{ng} / \mathrm{ml})$, and 2,4-D (0.6 $\mathrm{ng} / \mathrm{ml}$ vs. $1.1 \mathrm{ng} / \mathrm{ml})$ were lower than the U.S. population-based sample, whereas 95th percentile urinary concentrations of 4-F-3-PBA (both $<\mathrm{LOD}=0.1 \mathrm{ng} / \mathrm{ml}$ ), cis-DBCA (both $<\mathrm{LOD}=0.5 \mathrm{ng} / \mathrm{ml}$ ), and 2,4,5-T (both $<$ $\mathrm{LOD}=0.1 \mathrm{ng} / \mathrm{ml}$ ) were comparable in both cohorts.

The ICCs for urinary concentrations of DCBA uncorrected and corrected for SG were 0.60 (95\% CI: 0.45, 0.74 ) and 0.60 (95\% CI: 0.44, 0.73), respectively, demonstrating fair to good reproducibility. As shown in Figure 1, the distributions of urinary levels of DCBA were also not significantly different between the three time points measured. No ICCs or Friedman tests were calculated for the other analytes because detection frequencies were $<50 \%$.

Table 2 shows the associations between time of urine collection or demographic characteristics and urinary concentrations of pesticide biomarkers. There were no statistically significant associations between urinary concentrations of the analytes and time of urine collection (AM vs. PM) or woman's age ( $<24$ vs. $\geq 24$ years). However, less educated women ( $\leq 12$ years of education) were more likely to have greater urinary concentrations of DCBA ( $\beta$ : 0.9, 95\% CI: 0.1, 1.7; geometric means of less educated vs. more educated women: $8.0 \mathrm{ng} / \mathrm{ml}$ vs. $3.4 \mathrm{ng} / \mathrm{ml}$ ) and trans-DCCA (OR: 4.4, 95\% CI: 1.3, 15.6) compared with more educated women. Married women were more likely to have detectable urinary concentrations of 2,4-D (OR: 3.5, 95\% CI: 1.5, 8.4) relative to unmarried women. Unemployed women were also more likely to have detectable urinary concentrations of DHMB (OR: 2.7, 95\% CI: 1.1, 6.3) compared to employed women.

Shown in Table 3 are the associations between the consumption of select fruits, vegetables, or legumes in the past 48-hr and urinary concentrations of pesticide biomarkers. We found no statistically significant associations between urinary concentrations of the biomarkers and consumption of nearly all fruits, vegetables, and legumes. However, women that consumed collards (OR: 5.9, 95\% CI: 1.3, 26.7) or spinach (OR: 4.4, 95\% CI: $1.1,17.9)$ in the past 48-hr were more likely to have detectable urinary concentrations of 2,4-D relative to women that did not consume those foods in the past 48-hr. Associations between urinary concentrations of the pesticides biomarkers and the participants' consumption of other foods (Brussels sprouts, celery, or wine) in the past 48-hr were not assessed due to the low number of women who reported consuming those items.

Table 4 shows the associations between pest-related issues and urinary concentrations of pesticide biomarkers. There were no statistically significant associations if insects were a common nuisance in the home, pesticides had been applied outside the home by the participant or inside the home by a professional exterminator (regardless of time since last application), or pesticides were currently stored in the home. However, if the participant applied pesticides inside the home (regardless of time since last application), there was significant increase in the odds of having a detectable urinary concentration of trans-DCCA (OR: 4.9, 95\% CI: 1.1, 22.1) compared to other women. In addition, insect repellent use since becoming pregnant was positively associated with urinary concentrations of DCBA ( $\beta$ : 1.2, 95\% CI: 0.4, 2.0; geometric means of users vs. non-users: $8.3 \mathrm{ng} / \mathrm{ml}$ vs. $2.7 \mathrm{ng} / \mathrm{ml}$ ). Associations between urinary concentrations of the pesticides biomarkers and the participants' use of pet grooming products, pet flea/tick prevention applications, or pet flea/tick spray in the past 48-hr were not assessed due to the low number of women who reported use of those items.

Finally, the predictors that were statistically significant were simultaneously included in multivariate models for each biomarker that had more than one statistically significant predictor (e.g., 2,4-D in relation to both marital status and spinach or collards consumption). While this served to increase p-values somewhat due to reduced statistical power, effect estimates were similar (results not shown).

\section{Discussion}

To our knowledge, this is the first biomarker study to report on exposures to select pesticides among pregnant women in Puerto Rico, and also the first to report on temporal variability of DCBA, an oxidative metabolite of DEET. We found that 95th percentile urinary concentrations of DEET, 3-PBA, trans-DCCA, and 2,4-D were lower than urinary concentrations in women of reproductive age on the mainland U.S., whereas 95th percentile urinary concentrations of 4-F-3-PBA, cis-DBCA, and $2,4,5-\mathrm{T}$ were similar in both populations. We also found evidence that demographic factors, consumption of leafy greens, and pesticide use are potentially important determinants of exposure to certain pesticides among this group of pregnant women.

Aside from NHANES, there have been only a few studies in other pregnancy cohorts from around the world that have reported on urinary concentrations for some of these analytes [11-13,30,32,44]. Perhaps most relevant to our findings, in a study of pyrethroid exposures among pregnant women from 10 Caribbean countries 
(the authors did not include the Commonwealth of Puerto Rico), urinary detection frequencies for data across all countries were between $77-100 \%$ for cis-DBCA, transDCCA, 3-PBA, and 4-F-3-PBA [12]. In our study, detection frequencies were between $0-46.1 \%$ for the same group of metabolites. However, the LODs in the Caribbean study were about 1-2 orders of magnitude lower than those in our study, and, as a result, the greater detection frequency in the Caribbean study may not necessarily be equivalent to greater exposure. For example, it is notable that the 95th percentile urinary concentration of 3-PBA was $2.3 \mathrm{ng} / \mathrm{ml}$ in our study, compared to $0.54 \mathrm{ng} / \mathrm{ml}$ in the Caribbean study, which suggests that exposure to some pyrethroids may have been greater in our population.

The temporal reliability analysis for DCBA suggests that more than one spot sample may be needed to characterize exposure to DEET in pregnant women over the course of pregnancy. Thus, epidemiology studies conducted in pregnant women where the exposure assessment strategy relies on DCBA concentrations from a single spot sample will likely result in a moderate level of exposure misclassification, which, if non-differential, would underestimate (bias toward the null) true associations. In other published studies, temporal variability of urinary concentrations of the pesticides and pesticide metabolites assessed in our study has largely been unexplored, especially over a time period of several months which would be most relevant to pregnancy. ICCs for creatinine-corrected 3-PBA (0.85) and SG-corrected 2,4-D (0.57) associated with spot urine samples collected in Polish adults over seven consecutive days [45] and up to six spot urine samples collected in U.S. adults over a 48-hr period [46], respectively, have been reported.

We found that pregnant women were more likely to have detectable urinary concentrations of DHMB if they were unemployed. One hypothesis explaining this finding is that unemployed women may spend more time outdoors (e.g., gardening, exercising), thus necessitating increased use of insect repellents containing DEET, relative to working women. We had questionnaire information on weekly exercise and chore frequency and duration, which may correlate with outdoor activities, but further investigation of these variables with respect to employment status did not reveal any notable relationships (data not shown).

Participants in our study were also more likely to have detectable urinary concentrations of the herbicide 2,4-D if they were married. One plausible explanation is that married women might be more likely to be home owners relative to unmarried women and, as a result, might be more likely to be involved with home upkeep activities, such as controlling weed growth with herbicides containing 2,4-D. Unfortunately, information on home ownership was not collected so this hypothesis could not be explored further. Positive relationships between being married or living in an owned residence and urinary concentrations of 3-PBA, a non-specific metabolite of several pyrethroid insecticides, among U.S. pregnant women have been reported [30].

In addition, less educated women in our study were more likely to have greater urinary concentrations DCBA and trans-DCCA than other women, a finding supported by other studies for trans-DCCA [13], but not 3-PBA [30]. One hypothesis is that compared with more educated women, less educated women had lower household incomes, which resulted in lifestyle patterns (e.g., insufficient income to purchase organic produce) and/or conditions (e.g., living in poorer communities with decreased access to organic produce) with increased risk of exposure. For example, in a study of U.S. adults [47], consumption of organic produce was shown to increase with both educational attainment and household income levels, which supports our hypothesis.

Furthermore, we found a positive association between participants' use of pesticides at home and urinary concentration of trans-DCCA. Similar findings have been observed with pyrethroid metabolites in pregnant Chinese women [13], but not in Italian adults [31]. Use of insect repellents since becoming pregnant was also a positive predictor of urinary concentrations of DCBA, which is a novel finding that may validate DCBA as a biomarker of DEET exposure.

Participants in our study were also more likely to have detectable urinary concentrations of 2,4-D if they consumed collards or spinach in the past 48-hr. Consumption of unspecified "leafy greens" [31] or unspecified "dark green vegetables" [10] has also been reported in adults to be positively associated with urinary concentrations of 3-PBA. Consistent with our analysis, no associations between age and urinary concentrations of 3-PBA and transDCCA have been reported by others $[10,13,30,31]$.

Several strengths of our study include focusing on an understudied and potentially at-risk population, evaluating biomarkers of understudied exposures, and the collection of repeated data, which allowed for a powerful analysis where each participant served as her own reference in longitudinal models. One primary limitation was the lack of detailed questionnaire information, especially information on how demographic characteristics and pesticide use may lead to increased exposures. Although information of this kind would have assisted with understanding our findings, the increase in detail on the questionnaires would have increased participant burden and may have resulted in reduced participation and study compliance or potentially introduced added recall error. The interpretation of our findings was also further complicated by limited publicly-available information on pesticide use patterns in Puerto Rico. Additional limitations which 
precluded further quantitative analyses included the modest sample size $(\mathrm{N}=54)$, the small number of participants reporting consumption of certain food items or performing certain pest-related activities, and the relatively low detection frequencies $(<50 \%)$ of most urinary biomarkers. Finally, it should be noted that the results of our study may not be generalizable to other populations, especially of young children, because interaction with sources of pesticides and/or their metabolism of pesticides may be different from those of pregnant women or other adults.

\section{Conclusions}

We showed that pesticide use in a group of Puerto Rican pregnant women is associated with exposure to several pesticides. We also showed that when using DCBA as a specific urinary biomarker of DEET, if possible, more than one sample should be collected over the course of the pregnancy to minimize exposure measurement error. We demonstrated that among these Puerto Rican pregnant women being married, not employed, or less educated was associated with certain biomarkers of exposure to pesticides and should be further investigated to understand what aspects of these demographic characteristics lead to greater exposures. Consumption of collards, spinach, and potentially other leafy greens may also be important determinants of exposure to certain pesticides. Because human exposure to pesticides may be associated with adverse health effects, further research will increase our understanding of the drivers of pesticide exposure among pregnant women.

\section{Abbreviations \\ CDC: Centers for disease control and prevention; Cl: Confidence interval; 2,4-D: 2,4-dichlorophenoxyacetic acid; DBCA: cis-3-(2,2-dibromovinyl)-2,2- dimethylcyclopropane carboxylic acid; DCBA: 2-diethyl-carbamoyl benzoic acid; DCCA: Trans-3-(2,2-dichlorovinyl)-2,2-dimethylcyclopropane carboxylic acid; DEET: N-N-diethyl-meta-toluamide; DHMB: N,N-diethyl-3- hydroxymethylbenzamide; 4-F-3-PBA: 4-fluoro-3-phenoxybenzoic acid; ICC: Intraclass correlation coefficient; LOD: Limit of detection; NHANES: National health and nutrition examination survey; $\mathrm{NIH}$ : National institutes of health; OR: Odds ratio; 3-PBA: 3-phenoxybenzoic acid; PROTECT: Puerto Rico testsite for exploring contamination threats; SG: Specific gravity; 2,4,5-T: 2,4,5- trichlorophenoxyacetic acid.}

\section{Competing interests}

The authors declare that they have no competing interests.

\section{Authors' contributions}

$\mathrm{RL}$ conducted the statistical analyses, interpreted the results, and drafted the manuscript. DC managed the dataset and ran initial statistical analyses. LA, $\mathrm{JC}$ and $\mathrm{AA}$ directed participant recruitment and data collection, and contributed to the manuscript. AC, LVB, MD, and SB measured the urinary biomarkers and contributed to the manuscript. JM conceived the study, interpreted the results, and participated in drafting the manuscript. All authors read and approved the final manuscript.

\section{Acknowledgements}

Work was supported by grants P42ES017198 and P30ES017885 from the National Institute of Environmental Health Sciences, National Institutes of Health (NIH), and by grants G12MD007600 and U54MD007587 from the
National Institute on Minority Health and Health Disparities, NIH. The content is solely the responsibility of the authors and does not necessarily represent the official position of NIH or CDC. We thank Amanda Bishop, Pilar Morales-Agudelo, William Roman, Erin Wade and Charlie Chambers of CDC for their technical support with the urinalysis.

\section{Author details}

${ }^{1}$ Department of Environmental Health Sciences, University of Michigan School of Public Health, 1415 Washington Heights, Ann Arbor, Ml 48109, USA. ${ }^{2}$ Department of Obstetrics and Gynecology, Brigham and Women's Hospital, 75 Francis Street, Boston, MA 02115, USA. ${ }^{3}$ University of Puerto Rico Graduate School of Public Health, Medical Sciences Campus, San Juan 00935, Puerto Rico. ${ }^{4}$ Centers for Disease Control and Prevention, National Center for Environmental Health, Division of Laboratory Sciences, 4770 Buford Highway, Atlanta 30341, GA, USA. ${ }^{5}$ College of Engineering, Northeastern University, 360 Huntington Avenue, Boston, MA 02115, USA.

Received: 22 October 2014 Accepted: 5 November 2014 Published: 19 November 2014

\section{References}

1. U.S. Environmental Protection Agency: What is a pesticide? [http://www. epa.gov/pesticides/about]

2. Roberts JR, Reigart JR: Recognition and Management of Pesticide Poisonings. 6th edition. Washington, D.C: U.S. Environmental Protection Agency; 2004.

3. Arbuckle TE, Cole DC, Ritter L, Ripley BD: Farm children's exposure to herbicides: comparison of biomonitoring and questionnaire data. Epidemiology 2004, 15:187-194.

4. Arcury TA, Grzywacz JG, Barr DB, Tapia J, Chen H, Quandt SA: Pesticide urinary metabolite levels of children in eastern North Carolina farmworker households. Environ Health Perspect 2007, 115:1254-1260.

5. Babina K, Dollard M, Pilotto L, Edwards JW: Environmental exposure to organophosphorus and pyrethroid pesticides in South Australian preschool children: a cross sectional study. Environ Int 2012, 48:109-120.

6. Ding G, Shi R, Gao Y, Zhang Y, Kamijima M, Sakai K, Wang G, Feng C, Tian Y: Pyrethroid pesticide exposure and risk of childhood acute lymphocytic leukemia in Shanghai. Environ Sci Technol 2012, 46:13480-13487.

7. Panuwet P, Prapamontol T, Chantara S, Barr DB: Urinary pesticide metabolites in school students from northern Thailand. Int J Hyg Environ Health 2009, 212:288-297.

8. Rodríguez T, van Wendel de Joode B, Lindh CH, Rojas M, Lundberg I, Wesseling C: Assessment of long-term and recent pesticide exposure among rural school children in Nicaragua. Occup Environ Med 2012, 69:119-125.

9. Imai K, Yoshinaga J, Yoshikane M, Shiraishi H, Mieno MN, Yoshiike M, Nozawa S, Iwamoto T: Pyrethroid insecticide exposure and semen quality of young Japanese men. Reprod Toxicol 2014, 43:38-44.

10. McKelvey W, Jacobson JB, Kass D, Barr DB, Davis M, Calafat AM, Aldous KM: Population-based biomonitoring of exposure to organophosphate and pyrethroid pesticides in New York City. Environ Health Perspect 2013, 121:1349-1356.

11. Castorina R, Bradman A, Fenster L, Barr DB, Bravo R, Vedar MG, Harnly ME, McKone TE, Eisen EA, Eskenazi B: Comparison of current-use pesticide and other toxicant urinary metabolite levels among pregnant women in the CHAMACOS cohort and NHANES. Environ Health Perspect 2010, 118:856-863.

12. Dewailly E, Forde M, Robertson L, Kaddar N, Laouan Sidi EA, Côté S, Gaudreau E, Drescher O, Ayotte P: Evaluation of pyrethroid exposures in pregnant women from 10 Caribbean countries. Environ Int 2014, 63:201-206

13. Qi X, Zheng M, Wu C, Wang G, Feng C, Zhou Z: Urinary pyrethroid metabolites among pregnant women in an agricultural area of the Province of Jiangsu, China. Int J Hyg Environ Health 2012, 215:487-495.

14. Wickerham EL, Lozoff B, Shao J, Kaciroti N, Xia Y, Meeker JD: Reduced birth weight in relation to pesticide mixtures detected in cord blood of full-term infants. Environ Int 2012, 47:80-85.

15. Barr DB, Ananth CV, Yan X, Lashley S, Smulian JC, Ledoux TA, Hore P, Robson MG: Pesticide concentrations in maternal and umbilical cord sera and their relation to birth outcomes in a population of pregnant women and newborns in New Jersey. Sci Total Environ 2010, 408:790-795. 
16. Ostrea EM Jr, Bielawski DM, Posecion NC Jr, Corrion M, Villanueva-Uy E, Bernardo RC, Jin Y, Janisse JJ, Ager JW: Combined analysis of prenatal (maternal hair and blood) and neonatal (infant hair, cord blood and meconium) matrices to detect fetal exposure to environmental pesticides. Environ Res 2009, 109:116-122.

17. Corcellas C, Feo ML, Torres JP, Malm O, Ocampo-Duque W, Eljarrat E, Barceló D: Pyrethroids in human breast milk: occurrence and nursing daily intake estimation. Environ Int 2012, 47:17-22.

18. Feo ML, Eljarrat E, Manaca MN, Dobaño C, Barcelo D, Sunyer J, Alonso PL, Menendez C, Grimalt JO: Pyrethroid use-malaria control and individual applications by households for other pests and home garden use. Environ Int 2012, 38:67-72.

19. Stürtz N, Bongiovanni B, Rassetto M, Ferri A, de Duffard AM, Duffard R: Detection of 2,4-dichlorophenoxyacetic acid in rat milk of dams exposed during lactation and milk analysis of their major components. Food Chem Toxicol 2006, 44:8-16.

20. California Environmental Protection Agency (CA EPA): Public Health Goals for Chemicals in Drinking Water: 2,4-Dichlorophenoxyacetic Acid. Sacramento: CA EPA; 2009.

21. California Environmental Protection Agency (CA EPA): N,N,-DiethylMeta-Toluamide (DEET) Risk Characterization Document. Sacramento: CA EPA; 2000.

22. Agency for Toxic Substances and Disease Registry (ATSDR): Toxicology Profile for Pyrethrins and Pyrethroids. Atlanta: ATSDR; 2003.

23. Hardell L, Eriksson M: A case-control study of non-Hodgkin lymphoma and exposure to pesticides. Cancer 1999, 85:1353-1360.

24. McDuffie HH, Pahwa P, McLaughlin JR, Spinelli JJ, Fincham S, Dosman JA, Robson D, Skinnider LF, Choi NW: Non-Hodgkin's lymphoma and specific pesticide exposures in men: cross-Canada study of pesticides and health Cancer Epidemiol Biomarkers Prev 2001, 10:1155-1163.

25. Meeker JD, Barr DB, Hauser R: Human semen quality and sperm DNA damage in relation to urinary metabolites of pyrethroid insecticides. Hum Reprod 2008, 23:1932-1940.

26. Perry MJ, Venners SA, Barr DB, Xu X: Environmental pyrethroid and organophosphorus insecticide exposures and sperm concentration. Reprod Toxicol 2007, 23:113-118.

27. Swan SH, Kruse RL, Liu F, Barr DB, Drobnis EZ, Redmon JB, Wang C, Brazil C, Overstreet JW, Study for Future Families Research Group: Semen quality in relation to biomarkers of pesticide exposure. Environ Health Perspect 2003, 111:1478-1484.

28. Toshima H, Suzuki Y, Imai K, Yoshinaga J, Shiraishi H, Mizumoto $Y$ Hatakeyama S, Onohara C, Tokuoka S: Endocrine disrupting chemicals in urine of Japanese male partners of subfertile couples: a pilot study on exposure and semen quality. Int J Hyg Environ Health 2012, 215:502-506.

29. Meeker JD, Barr DB, Hauser R: Pyrethroid insecticide metabolites are associated with serum hormone levels in adult men. Reprod Toxicol 2009, 27:155-160.

30. Berkowitz GS, Obel J, Deych E, Lapinski R, Godbold J, Liu Z, Landrigan PJ Wolff MS: Exposure to indoor pesticides during pregnancy in a multiethnic, urban cohort. Environ Health Perspect 2004, 111:79-84.

31. Fortes C, Mastroeni S, Pilla MA, Antonelli G, Lunghini L, Aprea C: The relation between dietary habits and urinary levels of 3-phenoxybenzoic acid, a pyrethroid metabolite. Food Chem Toxicol 2013, 52:91-96.

32. Zhang J, Hisada A, Yoshinaga J, Shiraishi H, Shimodaira K, Okai T, Noda Y, Shirakawa M, Kato N: Exposure to pyrethroids insecticides and serum levels of thyroid-related measures in pregnant women. Environ Res 2013, 127:16-21.

33. Cantonwine DE, Meeker JD, Cordero JF, McElrath TF: Shifting gestational age distributions among singleton births in Puerto Rico: 1994-2009. Reprod Sci 2014, 21:309A.

34. Environmental Protection Agency (US EPA): In settlement with U.S., Puerto Rico farm pays fine and changes the way it applies pesticides; agrees to relief measures to protect local residents from drift (News Releases). Washington, DC: US EPA; 2001.

35. Environmental Protection Agency (US EPA): EPA adds Pesticide Warehouse III site in Manati to the Superfund National Priorities List (News Releases). Washington, DC: US EPA; 2003.

36. Environmental Protection Agency (US EPA): EPA draws attention to hazards of illegal pesticides in Puerto Rico (News Releases). Washington, DC: US EPA; 2004.

37. Environmental Protection Agency (US EPA): EPA cites pesticides practices of Puerto Rico Agency (News Releases). Washington, DC: US EPA; 2008
38. Cantonwine DE, Cordero JF, Rivera-González LO, Anzalota Del Toro LV, Ferguson KK, Mukherjee B, Calafat AM, Crespo N, Jiménez-Vélez B, Padilla IY, Alshawabkeh AN, Meeker JD: Urinary phthalate metabolite concentrations among pregnant women in Northern Puerto Rico: distribution, temporal variability, and predictors. Environ Int 2014, 62:1-11.

39. Meeker JD, Cantonwine DE, Rivera-González LO, Ferguson KK, Mukherjee B, Calafat AM, Ye X, Anzalota Del Toro LV, Crespo-Hernández N, Jiménez-Vélez B, Alshawabkeh AN, Cordero JF: Distribution, variability, and predictors of urinary concentrations of phenols and parabens among pregnant women in Puerto Rico. Environ Sci Technol 2013, 47:3439-3447.

40. Kuklenyik P, Baker SE, Bishop AM, Morales-A P, Calafat AM: On-line solid phase extraction-high performance liquid chromatography-isotope dilution-tandem mass spectrometry approach to quantify $\mathrm{N}, \mathrm{N}$-diethylm-toluamide and oxidative metabolites in urine. Anal Chim Acta 2013, 787:267-273.

41. Davis MD, Wade EL, Restrepo PR, Roman-Esteva W, Bravo R, Kuklenyik P, Calafat AM: Semi-automated solid phase extraction method for the mass spectrometric quantification of 12 specific metabolites of organophosphorus pesticides, synthetic pyrethroids, and select herbicides in human urine. J Chromatogr B Analyt Technol Biomed Life Sci 2013, 929:18-26.

42. Hankinson SE, Manson JE, Spiegelman D, Willett WC, Longcope C, Speizer FE: Reproducibility of plasma hormone levels in postmenopausal women over a 2-3-year period. Cancer Epidemiol Biomarkers Prev 1995, 4:649-654.

43. Rosner B: Multisample inference. In Fundamentals of Biostatistics. 5th edition. Edited by Rosner B. Pacific Grove: Duxbury; 2000:511-576.

44. Xue Z, Li X, Su Q, Xu L, Zhang P, Kong Z, Xu J, Teng J: Effect of synthetic pyrethroid pesticide exposure during pregnancy on the growth and development of infants. Asia Pac J Public Health 2013, 25(4 Suppl):72S-79S.

45. Wielgomas B: Variability of urinary excretion of pyrethroid metabolites in seven persons over seven consecutive days - implications for observational studies. Toxicol Lett 2013, 221:15-22.

46. Morgan MK, Sheldon LS, Thomas KW, Egeghy PP, Croghan CW, Jones PA, Chuang JC, Wilson NK: Adult and children's exposure to 2,4-D from multiple sources and pathways. J Expo Sci Environ Epidemiol 2008, 18:486-494.

47. Curl CL, Beresford SA, Hajat A, Kaufman JD, Moore K, Nettleton JA, Diez-Roux AV: Associations of organic produce consumption with socioeconomic status and the local food environment: Multi-Ethnic Study of Atherosclerosis (MESA). PLoS One 2013, 8:e69778.

doi:10.1186/1476-069X-13-97

Cite this article as: Lewis et al:: Urinary biomarkers of exposure to insecticides, herbicides, and one insect repellent among pregnant women in Puerto Rico. Environmental Health 2014 13:97.

\section{Submit your next manuscript to BioMed Central and take full advantage of:}

- Convenient online submission

- Thorough peer review

- No space constraints or color figure charges

- Immediate publication on acceptance

- Inclusion in PubMed, CAS, Scopus and Google Scholar

- Research which is freely available for redistribution 